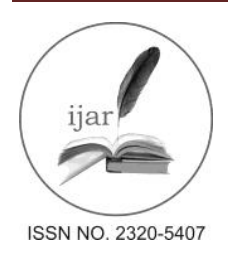

Journal homepage: http://www.journalijar.com

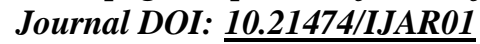

INTERNATIONAL JOURNAL

OF ADVANCED RESEARCH

RESEARCH ARTICLE

\title{
A REVIEW \& COMPARATIVE STUDY OF DIFFERENT ROUTING PROTOCOLS IN AD HOC NETWORKS.
}

Sukhleen Jaggi and Vikas Wasson.

Department of Computer Science and Engineering \& Chandigarh University, Mohal, India.

\section{Manuscript Info}

Manuscript History:

Received: 15 April 2016

Final Accepted: 29 May 2016

Published Online: June 2016

Key words:

Ad-hoc networks, Wireless sensor

networks, Routing Protocols,

Reactive, Proactive.

*Corresponding Author

Sukhleen Jaggi.

\section{Abstract}

An ad-hoc network works on a frameless network in which collection of devices are supplied to wireless links via communication interfaces. Wireless sensor network is a type of wireless ad hoc network where sensors nodes are geographically distributed each having self-governing feature and that can be used for monitoring the physical conditions in a network then the gathered information report back to the destination. In this paper, different routing strategies have been classified according to their routing paths such as reactive, proactive and hybrid protocols. This paper examines various routing protocols covering their functionality along with their advantages and disadvantages and also present the performance comparison among these protocols is analyses.

Copy Right, IJAR, 2016,. All rights reserved.

\section{Introduction:-}

An Ad-hoc network ([1], [11]) is an assembly of different wireless devices that can be specified as nodes which are connected by wireless links and they also wants to communicate with each other without having any fixed predefined infrastructure. So far different routing protocols have been developed under the ad-hoc networks like Mobile Ad-hoc Networks (MANETs), Wireless Sensor Networks (WSNs), Vehicular Ad-hoc Networks (VANETs), etc [1]. In modern time, WSN [23] has become a tremendous research area. A WSN can be generally defined as a network of nodes, which is termed as sensor nodes, which helps to sense the environment \& can also be used to communicate the information gathered from the monitored fields especially through wireless links [2]. The data in this network is forwarded, probably via multiple hops, to a sink which may act as a controller or a monitor that can use it narrowly or is connected to the Internet through a Gateway. It has great applications, especially in remote environmental monitoring and target tracking. WSNs are classified into following i.e.: Flat and Hierarchical Architecture. In Flat Architecture, each node is performing a sensing task where all these nodes are peers. But in the hierarchical architecture, these nodes are organized as clusters. These cluster members then send their information to the sink node which will then transfer this information to the task manager or controller through a gateway i.e. known as the Internet. These nodes can either be stationary or move or they can either act as a homogeneous node or a heterogeneous node. All these nodes are provided with a wireless interface with that they can easily communicate to all the other nodes in the network. Following figure 1showing the basic building structure of WSN that includes sensor nodes, task controller or manager, sink node and Internet source.

The design of WSN depends somewhat on the application considering following factors such as the environment, lower network cost, reliable, self-reconfigurable, adaptable to changing network topology, scalable, less energy consumption. Sensor nodes are the devices that have the capability to detect changes in pressure, temperature, sound, humidity, etc. Thus, there is need to develop a routing method that can overcome a WSN scalability issue without affecting the overall performance of a network.

The main tasks of WSN routing protocols are route generation, selection, and maintenance, so, therefore, distinct protocols have been proposed so far. 


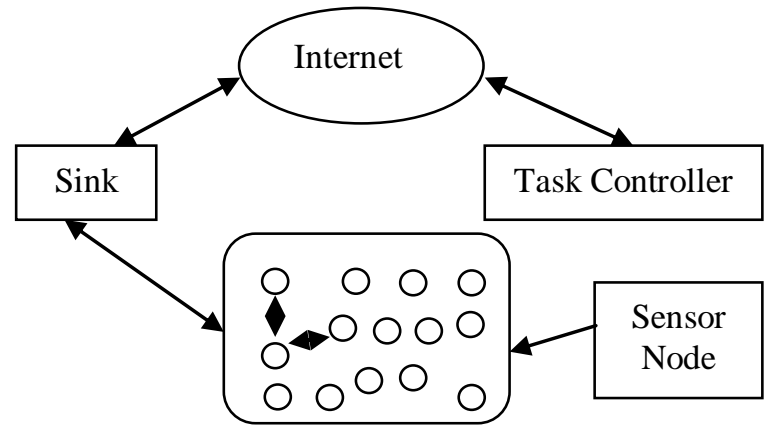

Figure 1. Architecture of WSN

These routing protocols in ad hoc network [3] can be categorized by three ways i.e. reactive, proactive, and hybrid protocols. Ad hoc On-Demand Distance Vector (AODV) and Dynamic Source Routing (DSR) protocols are covering under reactive protocols, Fisheye State Routing (FSR), Optimized Link-Sate Routing (OLSR) and Destination-Sequenced Distance-Vector Routing (DSDV) protocols including under proactive protocols and however zone routing protocol (ZRP) is a hybrid protocol showing under the following figure 2.

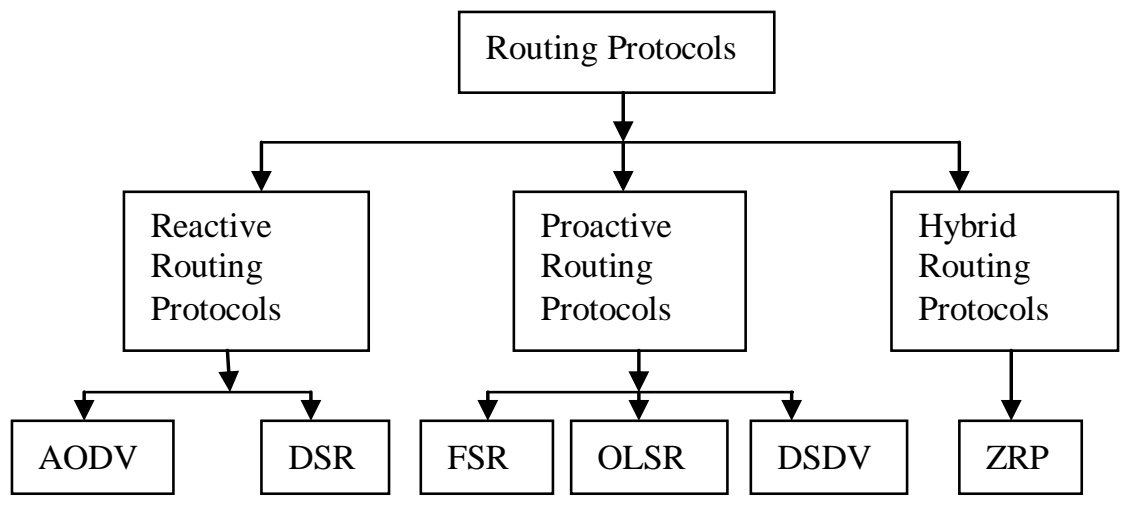

Figure 2. Types of routing protocols in ad hoc network

The proactive protocols are table driven routing protocols that need to maintain up-to-date routing information for all the nodes in a network. At least each node should maintain one routing table for storing the routing information in it and whenever there is any change in topology the routing protocol need to update at that time i.e. periodic updates are required during any change in the topology. Advantages of this routing are that it will lower route setup latency and delay in such network are less and disadvantages are high routing overhead and highly dynamic topologies.

Reactive protocols are on-demand routing protocols here a route is established only when it is demanded by a source node to forward a packet to the destination. In this mechanism, initially a route discovery process is performed and when the desired route is obtained when the process gets terminated. Advantages of this type are that it has lower routing overhead and disadvantages are high route setup latency.

Hybrid routing is a fusion of both table-driven and on-demand i.e. proactive and reactive protocols.

The reminder of our paper is formulated as follows. Section 2 provides a brief summary of ad hoc routing protocols, including their advantages and disadvantages. Section 3 prevents the comparison between reactive, proactive and hybrid routing protocols. Section 4 offers conclusion remarks.

\section{Summary of ad hoc routing protocols:- \\ Reactive Routing Protocols:-}

These protocols [12] are source-initiated where a process of discovering routes is initialized by the source node only when it is required for forwarding packets to the destination. For establishing the routes, it floods the network with a query i.e. Route Request (RREQ) and Route Reply (RREP). This process ends only when the required route is found 
or all possible alterations have been investigated. After the route setup process is done, but when a link failure exists then the route maintenance process comes out. Some reactive routing protocols are AODV, DSR protocols etc.

Ad-hoc On-demand Distance Vector (AODV) Routing Protocol: AODV ([4], [12], [19]) is based on distance-vector routing protocols where every node is maintaining its vector table i.e. distance-vector for all the nodes so that they knows about its neighboring node with their costs to reach those paths. In AODV protocol, every node wants to transmit a packet even when having no route available to forward these packets to a destination node than the source node will initiate a route discovery process. AODV holds two phases: Route Discovery and Maintenance. Another characteristic feature of AODV supports unicast, multicast and broadcast communication.

The AODV routing protocol uses different types of control messages that are as following: RREQ message for broadcasting messages to another node, RREP message for message reception, Route Error (RERR) messages for link failure notification and HELLO messages for evaluation and detection of links. AODV routing works by using RREQ and RREP messages. When the source node wishes to construct a route to the destination node which is not available in its transmission range, it will simply broadcast an RREQ packet to the whole network until the destination is achieved. Upon reception of RREQ packet, destination node will reply back with an RREP packet to the source node that the packet has successfully arrived at the destination node; hence, this process is known as route discovery process. When a route is active, the route maintenance process gets initiated only when a link breakage occurs then a detected node will notify the source node with an RERR packet that the destination is unreachable. Upon receiving the RERR, the source node will generate a new RREQ packet for discovering the destination node.

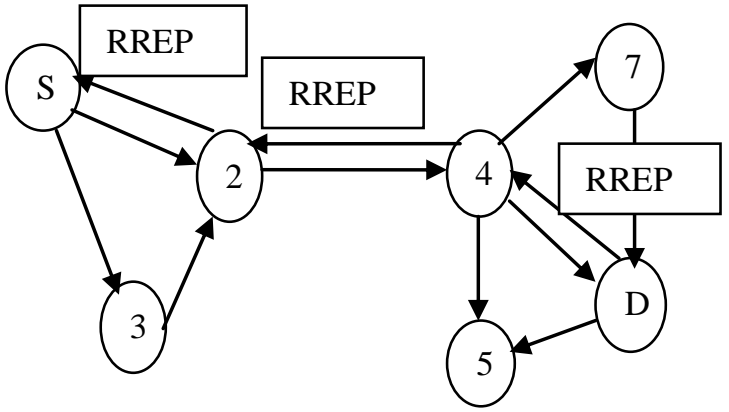

Figure 3. AODV Route Discovery Process

Advantages of AODV protocol are as follows:

* AODV minimizes the traffic overhead and routing overhead.

* It has lower setup delay.

* AODV is an efficient protocol as it consumes less bandwidth and energy.

* It has a loop-free route which in turn avoids the problem of a count to infinity.

Disadvantages of AODV protocol are as follows:

* AODV route discovery latency is high especially in the case of large networks.

* More occupation of network bandwidth, because of excessive flooding of RREQ \& RREP packets for finding out a valid route.

* AODV takes more time to build the routing tables.

Dynamic Source Routing (DSR): DSR ([12], [19]) protocol is based on the link-state algorithm employing where all the nodes are efficient as it has a complete network topology or routing information that is from source to a destination. This type of protocol is specially built in a simple and efficient designed manner for its usage in a multihop network where nodes are mobile. Rather than relying on the routing table, it uses a source routing technique.

DSR is utilizes two processes:

1. Route discovery

2. Route maintenance.

Route Discovery process is carried out using two messages i.e. RREQ and RREP message. In this process, whenever a node has data to send from source node to a destination node, then it will flood RREQ message dynamically to all 
the alternative nodes that are arriving at the destination node. Upon receiving RREQ, destination node will send an RREP to the original source node. In Route Maintenance process, an RERR message is used to inform a node if there is any broken line path in a network, then that message cannot reach the destination node. Further, this route discovery will be processed to find out a new route when it is still needed.

Advantages of DSR protocol are as follows:

* Reduces overhead of routing maintenance by maintaining routes within only those nodes who needs to communicate.

* Lesser overhead results from route discovery procedure.

* It helps in reducing the routing load where a single route may turn to many routes to the destination.

Disadvantages of DSR protocol are as follows:

* In the case of a broken connection, the route maintenance process does not restrictedly repair it.

* In DSR delay for route establishment is very high.

* Route replies blast problems.

* Due to route length of source routing, the size of packet header increases.

\section{Proactive Routing Protocols:-}

These table-driven protocols are used to store the routing information periodically in the node's routing table. The main contribution to this protocol is to preserve a consistent and freshness routing information of all the nodes in a network. In this routing, each node broadcasts its routing table to every node in its neighbourhood. Whenever the topology of a network changes then all nodes in a network will propagate the route updates to maintain a stable network view. Examples of these routing protocols are OLSR, FSR, etc.

Fisheye State Routing (FSR): FSR protocol uses a table-driven mechanism and is also implied as a hierarchical routing protocol. This protocol ([5], [12]) is using a fisheye technique which helps to reduce the routing overhead. Here in this technique, the fish eye's is taking the pixel information which is having a higher accuracy value near the eye's focal point. Hence, this accuracy value of a pixel is decreasing with the increase in the distance from its focal point. Routing in this fisheye approach has the ability to translate and maintain the accurate information only of its near nodes rather than the far-away nodes in its network. This protocol works as a proactive protocol which helps to maintain the topology of a network at every node, rather than flooding the topology information in an entire network. Alternatively, these nodes are maintaining a link state table which is based only on the information acquired from their neighbor nodes. Hence, every node in the network has complete network information which helps in providing a quick and efficient routing establishment. With the increase in network size, the nodes will consume more bandwidth. So, routing scopes are introduced in FSR especially for reducing the message size. A scope is a set of nodes that can reach to every node in a network within a given number of hops. Therefore, this protocol is best suited especially for large and highly mobile network environments.

Advantages of FSR protocol are as follows:

* It is only suitable for those environments that are large and highly mobile.

* FSR reduces routing overhead.

* Message size of the topology information is reduced by concerning far-away nodes.

Disadvantages of FSR protocol are as follows:

* The performance of the network will degrade when the zone length of the FSR increases.

* Small ad-hoc networks will provide poor protocol performance.

Optimized Link-Sate Routing (OLSR) Routing Protocol: An OLSR ([6]-[7], [12]) protocol is an optimized routing protocol for MANETs and it can also be useful for a wireless ad-hoc network. It is a proactive protocol which is used only when a route is feasible directly when needed. OLSR routing protocol is based on link-state routing protocol where each node floods a neighbor's topology table information to all the other nodes in the network that formerly figure out an optimal forwarding path locally. So, OLSR protocol is used to reduce these flooding problems by using only Multipoint Relay (MPR) nodes this can be used to send information in the network. OLSR is also used to avoid unnecessary transmission of link-state packets i.e. once a packet is sent to a node, then that node will not going to obtain any another copy of the same packet during its transmission. Therefore, it will help to reduce the number of control packets by reducing duplicate transmissions. Hence in OLSR, each node will decide 
that which of its neighbors can flood these link-state packets, these nodes are named as MPR nodes. Only the MPR nodes are suggested to transmit these control traffic packet to the entire network. An MPR node will transmit an acknowledged message only if the component of the MPRs set of the neighbor node has transmitted the message. So, this set is known as MPR selectors where each node in its set is maintaining a set of the nodes from that selected nodes an MPR is selected and in this set, each node will retransmit only the acknowledged message from those nodes which are inside the MPR selectors set. OLSR routing protocol has four kinds of messages that are as follows: HELLO messages, Topology Control (TC) messages, Multiple Interface Declaration (MID) and Host and Network Announcement (HNA).

Advantages of OLSR protocol are as follows:

* OLSR protocol is also based on a flat routing protocol that means having no central administrative system is used for handling its routing process.

* OLSR protocol does not desire a reliable link for control messages, as these messages are being sent regularly and it does not have a sequential transmission.

* It is well suited for applications where there are short delays in the transmission of data packets.

* Its implementation is more user-friendly.

* It increases the protocol suitability for an ad-hoc network including the rapid change in source and destination pairs.

Disadvantages of OLSR protocol are as follows:

* It has wider delay distribution.

* OLSR routing protocol needs lots of time for re-discovering broken links.

* The requirement of processing power is large especially for discovering an alternate route.

Destination-Sequenced Distance-Vector (DSDV) Routing Protocol: DSDV ([8], [12], [13], [19]) is a proactive protocol i.e. routing information is available immediately from the routing tables and it works as a hop-by-hop distance vector routing protocol especially demanding all the nodes to periodically maintain its routing table, to find out all the relevant paths to reach the destination nodes and also finds number of hops in the network can be recorded. The main idea to this routing is to solve the routing loop problem. Here all the entries in routing table must include a sequence number. If when there is a link available in the network then only these sequence numbers are placed as an even otherwise an odd number is placed. Furthermore, this routing table information can be exchanged with every neighboring node so hence this routing data can be updated with new data by every node in the network. In DSDV protocol, buffering size is maximizes in this protocol and it is also present in memory for collecting those data packets that could not receive the information until the routing information is acknowledged at the destination.

Advantages of DSDV protocol:

* In this protocol, routing information available immediately from the routing table.

* DSDV guarantees a loop-free path.

* It reduces count-to-infinity problem.

- Space required for storing a routing table is reduced as DSDV maintains only the best path to reach the destination node.

Disadvantages of DSDV protocol:

- Multipath Routing is not suitable for this protocol.

* Difficult to determine a time delay in every route's advertisement.

* Wastage of bandwidth due to a redundant spreading of routing information even when the network topology does not change.

* For a larger network, DSDV finds huge difficulty in maintaining all the routing table advertisements.

* DSDV is not scalable in ad-hoc networks.

\section{Hybrid Routing Protocols:-}

This protocol merges features of both reactive and proactive protocols. It can also be defined as a routing protocol having the combination of both a distance-vector routing that operates by distributing its information of the entire network with all its neighboring nodes and also with a link-state routing that operates as a router to inform every router on the network about its closest neighbors. Hybrid routing protocols include following examples: ZRP, ZHLS (Zone-based Hierarchical Link State), TORA (Temporally-Ordered Routing Algorithm) protocols. This type of 
routing is basically used to define the best destination routes in the network along with the changes or modifications in the topology.

Zone Routing Protocol (ZRP): ZRP is a wireless networking hybrid protocol having characteristics like both of reactive and proactive routing schemes. In Zone based routing type, nodes proactively control all the routes to destinations which are inside its local neighborhoods that can be termed as routing zone. Routing zone is described as an assembly of all the nodes having a minimum distance in hops which is not greater than the zone radius. Here in this routing, each node is maintaining its zone radius and overlapping of neighboring zones occur. It is taking the advantage of the reactive routing protocol used for the communication between local neighborhoods nodes. A ZRP routing can be classified into two parts that are as follows:

* Intrazone Routing Protocol (IARP).

* Interzone Routing Protocol (IERP).

In an IARP includes a proactive protocol for maintaining the zone routing protocol inside the routing zone. Besides, an IERP uses a reactive protocol within its routing zone and it can also be used to discover routes to the destination reactively.

Advantages of ZRP Protocol:

* It displays better performance as in this routing protocol both the routing schemes are used i.e. proactive and reactive routing protocols.

- Compared to reactive routing it helps in reducing the bandwidth wastage and control overhead as well.

- Eliminate the delays for routing within a routing zone due to the route-discovery process used in the reactive protocol.

* It helps in reducing the control overheads for longer routes which is necessary while using proactive routing protocols throughout the entire route.

Disadvantages of ZRP Protocol:

* The main problem in this routing is the large overlapping of routing zones.

* It requires more memory as each node in the network is having a high-level topology information which may require greater memory requirements.

Comparison between reactive, proactive and hybrid protocols:-

Table 1. Comparison between reactive, proactive, and hybrid routing

\begin{tabular}{|c|c|c|c|}
\hline Parameters & Reactive Routing Protocol & $\begin{array}{l}\text { Proactive } \\
\text { Protocol }\end{array}$ & Hybrid Routing Protocol \\
\hline Description & $\begin{array}{l}\text { On-demand routing protocol } \\
\text { which establishes a route } \\
\text { especially when it is needed or } \\
\text { demanded by a node for } \\
\text { creating a route to a } \\
\text { destination }\end{array}$ & $\begin{array}{l}\text { Table-driven routing } \\
\text { protocol where the } \\
\text { information of all routes } \\
\text { are maintained in the } \\
\text { routing table }\end{array}$ & $\begin{array}{l}\text { It is a combination of both routing } \\
\text { protocols features i.e. reactive and } \\
\text { proactive protocols }\end{array}$ \\
\hline Routing philosophy & Flat & Flat & Hierarchical \\
\hline Overhead & Low & High & Reduces overhead \\
\hline Memory requirements & Low & High & Very high \\
\hline Delay & High & Low & Low \\
\hline Advantages & $\begin{array}{l}\text { Lower routing overhead, no } \\
\text { unnecessary control messages } \\
\text { are required }\end{array}$ & $\begin{array}{l}\text { Route setup latency is } \\
\text { very lower, in this case }\end{array}$ & $\begin{array}{l}\text { Having no route setup latency for } \\
\text { short distance connection, reduces } \\
\text { control overhead, minimizing } \\
\text { delays }\end{array}$ \\
\hline Disadvantages & $\begin{array}{l}\text { High latency for finding } \\
\text { routes, route discovery packet } \\
\text { flooding }\end{array}$ & $\begin{array}{l}\text { Maintaining cost is very } \\
\text { high for topology } \\
\text { information, high routing } \\
\text { overheads }\end{array}$ & $\begin{array}{l}\text { Overlapping of routing zones are } \\
\text { very large, large memory } \\
\text { requirements }\end{array}$ \\
\hline
\end{tabular}


Table 1 shows the basic comparison between Reactive, Proactive and Hybrid routing based on some of their parameters and also including a difference between their advantages and disadvantages. Following Table 2 is defining the comparison between each of the routing strategies protocols i.e. AODV, DSR, FSR, OLSR, and ZRP routing protocols and the results are discussed below.

Table 2. Comparative study of different routing protocols

\begin{tabular}{|c|c|c|c|c|c|c|}
\hline Parameters & AODV & DSR & FSR & OLSR & DSDV & ZRP \\
\hline $\begin{array}{l}\text { Routing } \\
\text { philosophy }\end{array}$ & On-demand & On-demand & Proactive & Proactive & Proactive & $\begin{array}{l}\text { Hybrid i.e. both } \\
\text { on-demand and } \\
\text { proactive in } \\
\text { nature }\end{array}$ \\
\hline $\begin{array}{l}\text { Routing } \\
\text { Overhead }\end{array}$ & $\begin{array}{l}\text { Higher as } \\
\text { compared to } \\
\text { DSDV }\end{array}$ & $\begin{array}{l}\text { High } \\
\text { overhead for } \\
\text { long paths or } \\
\text { large address }\end{array}$ & $\begin{array}{lr}\text { High routing } \\
\text { overhead } & \text { with } \\
\text { respect } & \text { to } \\
\text { scalability } & \\
\end{array}$ & Higher & Low & Low \\
\hline $\begin{array}{l}\text { Control } \\
\text { Overhead }\end{array}$ & Low & Low & $\begin{array}{l}\text { It helps in } \\
\text { reducing the } \\
\text { control message } \\
\text { overhead }\end{array}$ & $\begin{array}{l}\text { It minimizes } \\
\text { the overhead }\end{array}$ & \begin{tabular}{lr}
\multicolumn{2}{l}{ Performance } \\
varies within \\
AODV and \\
DSR routing \\
protocols
\end{tabular} & $\begin{array}{l}\text { Reduced } \\
\text { control } \\
\text { overhead for } \\
\text { longer routes }\end{array}$ \\
\hline Loop-free & $\begin{array}{l}\text { Supports } \\
\text { loop } \\
\text { freedom }\end{array}$ & Yes & Yes & Yes & Yes & Yes \\
\hline $\begin{array}{l}\text { End-to-end } \\
\text { delay }\end{array}$ & $\begin{array}{l}\text { Performance } \\
\text { decreases }\end{array}$ & $\begin{array}{l}\text { Better than } \\
\text { DSDV }\end{array}$ & Higher delay & $\begin{array}{l}\text { Wider delay } \\
\text { distribution }\end{array}$ & $\begin{array}{l}\text { Higher end-to- } \\
\text { end delay }\end{array}$ & $\begin{array}{l}\text { Eliminating } \\
\text { delays for } \\
\text { routing }\end{array}$ \\
\hline QoS Support & No & No & Yes & Yes & $\begin{array}{lr}\text { It does } & \text { not } \\
\text { support } & \text { QoS } \\
\text { services } & \end{array}$ & Yes \\
\hline $\begin{array}{l}\text { Route } \\
\text { maintained in }\end{array}$ & Route table & Route cache & Routing table & Routing table & Routing table & Routing zones \\
\hline $\begin{array}{l}\text { Hello } \\
\text { Messages }\end{array}$ & Yes & Yes & No & Yes & No & Yes \\
\hline Protocol type & $\begin{array}{l}\text { Distance- } \\
\text { vector }\end{array}$ & Link-state & Link-state & Link-state & Distance-vector & $\begin{array}{l}\text { Hierarchical } \\
\text { routing }\end{array}$ \\
\hline $\begin{array}{l}\text { Multipath } \\
\text { routing }\end{array}$ & No & Yes & Yes & No & $\begin{array}{ll}\text { It does not } \\
\text { support } \\
\text { multipath } \\
\text { routing }\end{array}$ & Yes \\
\hline Scalability & Low & Low & Limited & Good & Low & Good \\
\hline Mobility & Low & Low & Low & Limited & Good & Good \\
\hline $\begin{array}{l}\text { Periodic } \\
\text { broadcast }\end{array}$ & Yes & No & Yes & Yes & Yes & Yes \\
\hline $\begin{array}{l}\text { Unidirectional } \\
\text { link support }\end{array}$ & No & Yes & $\begin{array}{l}\text { It fully supports } \\
\text { unidirectional } \\
\text { link }\end{array}$ & Yes & No & Yes \\
\hline $\begin{array}{l}\text { Caching } \\
\text { overhead }\end{array}$ & Low & $\begin{array}{l}\text { Less } \\
\text { overhead }\end{array}$ & Low & $\begin{array}{l}\text { Very low } \\
\text { overhead }\end{array}$ & $\begin{array}{l}\text { Lesser } \\
\text { overhead of } \\
\text { DSDV }\end{array}$ & $\begin{array}{l}\text { Reduce } \\
\text { processing } \\
\text { overhead }\end{array}$ \\
\hline
\end{tabular}

Conclusions:-

In this paper, we have given a description of several routing schemes proposed for mobile ad hoc networks or wireless sensor network as well. Classifications of these schemes are based on some routing strategy i.e. table-driven and on-demand and presented a comparison study related to these different types of routing protocols. All the tasks related to these routing processes are discussed in detail. Also, the advantages and disadvantages of all these routing 
protocols are discussed based on their routing processes. At the end of paper, a comparison is made between these protocols based on some parameters, their performance can be analyzed by these metrics and results are shown in the above-mentioned table.

\section{References:-}

1. Sarkar, T. G. Basavaraju, Subir Kumar, and C. Puttamadappa. Ad hoc mobile wireless networks: principles, protocols and applications. CRC Press, 2007.

2. Sohraby, Daniel Minoli, Kazem, and Taieb Znati. Wireless sensor networks: technology, protocols, and applications. John Wiley \& Sons, 2007.

3. Palaniammal, M., and M. Lalli. "Comparative study of routing Protocols for MANETs." International Journal of Computer Science and Mobile Applications 2, no. 2, pp. 118-127, 2014.

4. Patil, V. P. "Reactive and proactive routing protocol performance evaluation for qualitative and quantitative analysis in mobile ad hoc network." International Journal of Scientific and Research Publications 2, pp. 1-8, Vol No. 9, 2012.

5. Kilinkaridis, Theofanis. "Routing Protocols for Wireless Ad Hoc Networks."

6. Jacquet, Anis Laouiti, Amir Qayyum, Philippe, Paul Mühlethaler, Thomas Clausen, and Laurent Viennot. "Optimized link state routing protocol for ad hoc networks." IEEE INMIC 2001. Technology for the 21st Century. Proceedings. IEEE International, pp. 62-68. IEEE, 2001.

7. Clausen T, Jacquet P, RFC 3626-“Optimized Link State Routing Protocol (OLSR)”, Oct 2003.

8. Rai, Vijendra, and Jaishree Jain. "Study and Comparison Performance of On-demand AODV and DSR, along with the traditional proactive DSDV Routing Protocols for MANET." National Conference on Emerging Trends in Advanced Computer \& Informatics, Volume 2, Issue 6, 2012.

9. Basu Dev Shivahare, Charu Wahi, Shalini Shivhare. "Proactive And Reactive Routing Protocols In Mobile Adhoc Network Using Routing Protocol” ISSN 2250-2459, Volume 2, Issue 3, March 2012.

10. Dhote, C. A., R. S. Mangrulkar, M. A. Pund, and Mr Makarand R. Shahade. "Hybrid routing protocol with broadcast reply for mobile Ad hoc network." International Journal of Computer Applications 1, vol no. 10, 2010.

11. Murthy, C. Siva Ram, and B. S. Manoj. Ad Hoc Wireless Networks: Architectures and Protocols, Portable Documents. Pearson education, 2004.

12. Santa Barbara Elizabeth M. Royer and Chai Keong Toh. "A Review of Current Routing Protocols for Adhoc Mobile Wireless Networks.” IEEE Personal Communications, pages 46-55, April 1999.

13. C. P. P. Bhagwat. "Highly Dynamic Destination Sequenced Distance Vector DSDV Routing for Mobile Computers.” Proceeding of ACM SIGCOM, pages 234 - 244, September 1994.

14. Leanna, V. Y., and Basuki Rahmat. "Comparison of proactive and reactive routing protocol in mobile adhoc network based on "Ant-algorithm"." InComputer, Control, Informatics and Its Applications (IC3INA), International Conference on, pp. 153-158. IEEE, 2013.

15. Hong, Xiaoyan, Kaixin Xu, and Mario Gerla. "Scalable routing protocols for mobile ad hoc networks." Network, IEEE 16, vol no. 4, pp 11-21, 2002.

16. Prof. B.N. Jagdale, Prof. P. Lahane, Prof. Pragati Patil, Prof. D. Javale "Analysis and Comparison of Distance Vector, DSDV and AODV Protocol of MANET." International Journal of Distributed and Parallel Systems (IJDPS) Vol.3, No.2, 2012.

17. Mahmood, D., Nadeem Javaid, U. Qasim, Z. A. Khan, A. Khan, S. Qurashi, and A. Memon. "Modeling and Evaluating Performance of Routing Operations in Proactive Routing Protocols." arXiv preprint arXiv:1309.4389 (2013).

18. Rajeshkumar, V., and P. Sivakumar. "Comparative Study of AODV, DSDV and DSR Routing Protocols in MANET Using Network Simulator-2." International Journal of Advanced Research in Computer and Communication Engineering, Vol. 2, Issue 12, 2013.

19. Lego, Kapang, and Dipankar Sutradhar. "Comparative Study of Adhoc Routing Protocol AODV, DSR and DSDV in Mobile Adhoc NETwork 1." Indian Journal of Computer Science and Engineering, Vol. 1 No. 4 36437, 2011.

20. Malany, VR Sarma Dhulipala, A. Boomarani, and R. M. Chandrasekaran. "Throughput and delay comparison of MANET routing protocols." Int. J. Open Problems Compt. Math 2, no. 3, pp. 461-468, 2009.

21. Gupta, Sachin Kumar, and R. K. Saket. "Performance metric comparison of AODV and DSDV routing protocols in manets using ns-2." International Journal of Research and Reviews in Applied Sciences 7, no. 3, pp. 339-350, 2011. 
22. Khiavi, Shahram Jamali, Mina Vajed, and Sajjad Jahanbakhsh Gudakahriz. "Performance comparison of AODV, DSDV, DSR and TORA routing protocols in MANETs." International Research Journal of Applied and Basic Sciences 3, pp. 1429-1436, vol 7, 2012.

23. Akyildiz, Yogesh Sankarasubramaniam, Ian F., Weilian Su, and Erdal Cayirci. "A survey on sensor networks." Communications magazine, IEEE40, pp. 102-114, vol no. 8, 2002.

24. Khandakar, Amith. "Step by Step Procedural Comparison of DSR, AODV and DSDV Routing protocol." International Proceedings of Computer Science \& Information Tech, pp. 36, vol 40, 2012.

25. Bouhorma, H. Bentaouit, Mohammed, and A. Boudhir. "Performance comparison of ad-hoc routing protocols AODV and DSR." In Multimedia Computing and Systems, 2009. ICMCS'09. International Conference on, pp. 511-514, 2009. 